Discussion Papers
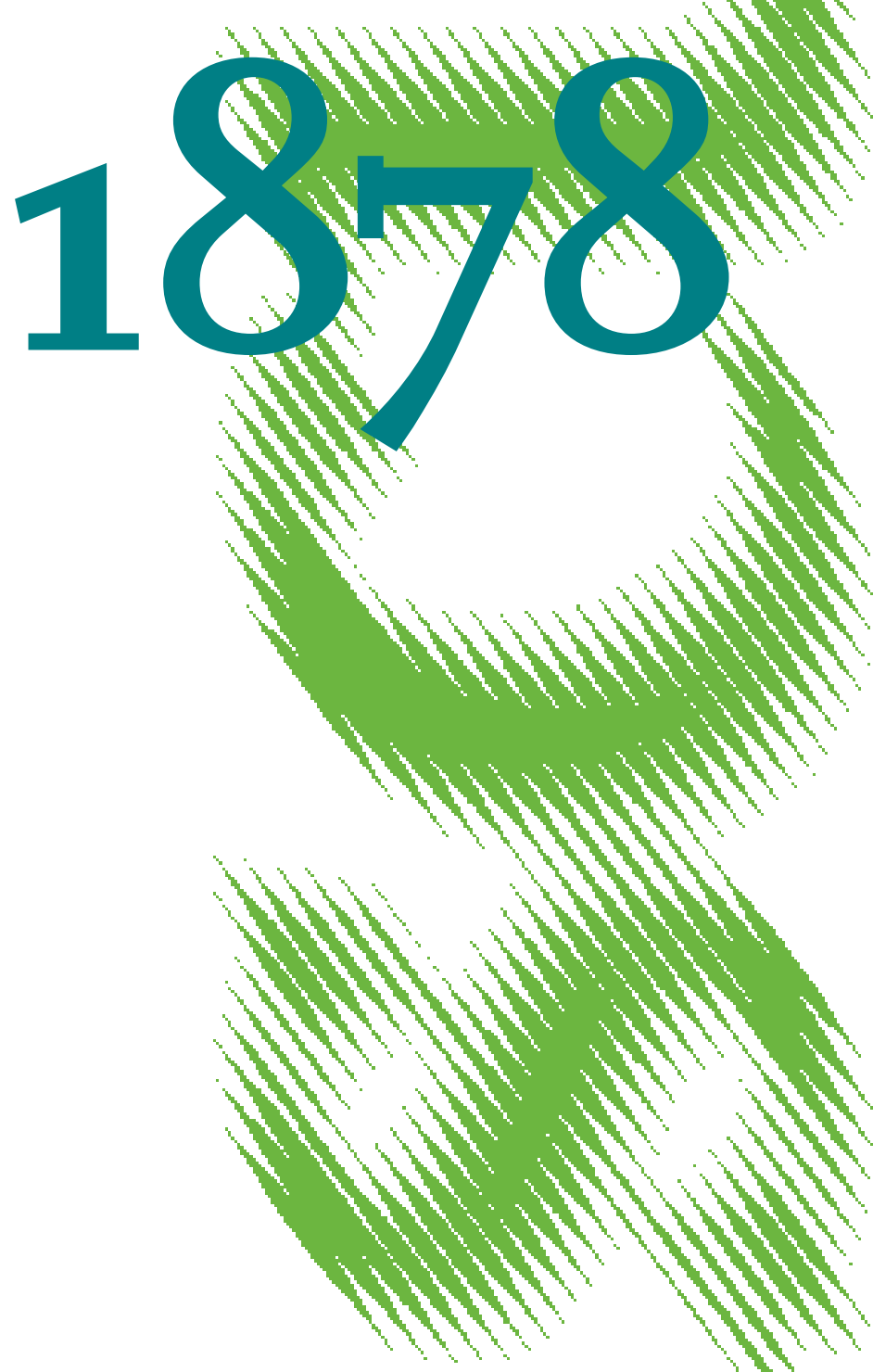

Waiting for My Sentence: Air Pollution and the Productivity of Court Rulings 
Opinions expressed in this paper are those of the author(s) and do not necessarily reflect views of the institute.

IMPRESSUM

(C) DIW Berlin, 2020

DIW Berlin

German Institute for Economic Research

Mohrenstr. 58

10117 Berlin

Tel. +49 (30) $89789-0$

Fax +49 (30) $89789-200$

http://www.diw.de

ISSN electronic edition 1619-4535

Papers can be downloaded free of charge from the DIW Berlin website:

http://www.diw.de/discussionpapers

Discussion Papers of DIW Berlin are indexed in RePEc and SSRN:

http://ideas.repec.org/s/diw/diwwpp.html

http://www.ssrn.com/link/DIW-Berlin-German-Inst-Econ-Res.html 


\title{
Waiting for my Sentence: Air Pollution and the Productivity of Court Rulings*
}

\author{
Luis Sarmiento $^{\dagger}$
}

I assert that air pollution from nitrogen oxides affects the productivity of employees in Mexican court hearings. This is the first article analyzing this connection and the first to disentangle work-breaks from the productivity of white-collar workers. I merge hourly pollution with granular hearing data under the assumption that the length of the hearing approximates productivity and identify causality from panel and instrumental variable techniques. Results show a loss of 3.83 workdays during the sample period due to the productivity shock stemming from comparing exposure at the hours with the highest and lowest concentration of nitrogen oxides in the data-set.

JEL codes: C23, J24, Q53

Keywords: Air pollution, nitrogen oxides, productivity, labor market effects.

${ }^{*}$ The air quality data used in this article can be obtained from the website for air quality monitoring in Mexico City http://www.aire.cdmx.gob.mx/default.php. The data on judicial hearings and air pollution for Monterrey through the website of the Mexican transparency portal https://www. plataformadetransparencia.org.mx/web/guest/inicio. Additional material will be provided in the online appendix.

${ }^{\dagger}$ German Institute of Economic Research, Berlin Institute of Technology, and Berlin School of Economics, Mohrenstrasse 58, 10117 Berlin, Germany. E-Mail: asarmiento@ diw.de, Ph.:+49-30-89789- 523. 


\section{Disclosure Statement}

Luis Sarmiento confirms to have support from the German Institute for Economic Research (DIW Berlin), where he holds a position as a research associate. However, no specific funds were used for the project entitled Waiting for my Sentence: Air Pollution and the Productivity of Court Rulings. Furthermore, Luis Sarmiento expresses no conflict of interests between this paper and his professional work. No other party had the right to review the paper prior to circulation. 


\section{Introduction}

Investigating the external factors that affect the productivity of high-skilled professions is important because service-driven societies produce output not only through the use of physical labor but also from the exploitation of cognitive skills. One of these external factors refers to air pollution in urban centers. If air pollution decreases the productivity of white-collar workers, it is important to understand the magnitude of this effect and evaluate its associated costs in order to include them in the cost-benefit analyses of environmental policies. Furthermore, the automation of repetitive tasks will boost the share of high skill professions and further increase the relevance of studies on the effect of air pollution on the productivity of white-collar activities 1

This article concentrates on one particular externality and one specific high-skill profession; air pollution in the form of nitrogen oxides $\left(N O_{x}\right)$ and lawyers, judges, and prosecutors participating in Mexican court hearings; in Mexico, only lawyers, judges, and prosecutors participate in the hearings, there is no jury, and the defendant rarely engages. The study is to the best of my knowledge, the first examining the relationship between productivity and nitrogen oxides, the first to concentrate on the very short-term (hourly) effect of pollution on productivity, and the first to explore the relationship between these two variables while controlling for discretionary breaks while working. I approximate productivity with the time it takes to settle each court case under the assumption that all things equal, two cases only varying in their level of exposure to nitrogen oxides would show different lengths because of the effects that $N O_{x}$ impose on participating individuals. ${ }^{2}$ Moreover, I defend the connection between exposure to nitrogen oxides, health, and productivity by analyzing current epidemiological literature on the effects of $N O_{x}$ on the human body. This extensive body of research contains suggestive evidence on the association between $N O_{x}$, respiratory health, and cognitive morbidity. Then, I develop a simplified model on the relationship between both variables and clarify why the length of the hearing is a suitable proxy for the productivity of court participants. In broad terms, I approximate productivity as a function of health and other relevant covariates under the central assumption that nitrogen oxides cripple the health of exposed persons and, as a

\footnotetext{
${ }^{1}$ For instance, David (2015) argues that incoming automation can increase the comparative advantage of workers supplying problem-solving abilities and creative skills to the labor force.

${ }^{2}$ Henceforth, I use trials and hearings interchangeably. However, there is a legal difference between both terms: Hearings determine if the judicial system should pursue the imposed charges while trials identify the guilt or innocence of indicted persons. For this article, the difference is not relevant, and both terms refer to any legal proceedings in the courtroom
} 
consequence, their productivity measure.

I use granular data Mexican judicial hearings to identify the causal effect of $N O_{x}$ on productivity. The data set contains the exact time the trial started and ended, judge identifiers, courthouse identifiers, geo-coordinates, crime typologies, hearing types, and final resolutions. The empirical strategy uses panel and instrumental variable (IV) techniques to explain variations in hearings' length as a function of exposure to nitrogen oxides. It controls for all consistent time-varying unobservables as traffic and lunch breaks with time fixed effects and for all time-consistent covariates with individual fixed effects. Further controls include the type of crime, workloads (which I approximate with the number of daily and hourly cases in the courthouse), the final resolution, the kind of hearing, weather covariates, macroeconomic variables, and additional pollutants. To reduce worries regarding misspecification, I also present results for an IV design that uses wind speed, wind direction, and atmospheric pressure as instruments to control for unobservable covariates biasing the results of the preferred specification. Finally, I analyze the impact of other measured contaminants, study different effects between violent and non-violent crimes, present three placebo tests to examine the consistency of the empirical methodology, and analyze the influence of lagged values.

Hearing times are a novel measure to approximate white-collar productivity because judicial hearings are one of the only purely-cognitive tasks that have time-measured output across space and time. Another advantage is that under normal circumstances, Mexican hearings cannot experience discretionary pauses. ${ }^{3}$ This feature allows me to concentrate on the productivity of employees while working, avoiding the noise of prolonged pauses on the productivity measure. The main issue when not accounting for prolonged breaks is that point estimates may be capturing extended brakes and not productivity losses while working. For instance, Chang et al. (2019) find that pollution affects the productivity of call center employees in Shanghai and Nanton by increasing the number and length of discretionary breaks. Another advantage of the data-set is that it allows me to analyze the effect of hourly variations in pollution on my productivity measure. Using hourly data reduces the correlation between nitrogen oxides and all other measured contaminants, enabling me to specify multipollutant models that can control for all other particles besides $N O_{x}$ and avoid spurious correlation between them. Additionally, using hourly data allows me to explore the effects of a previously ignored timewindow of exposure on productivity.

\footnotetext{
${ }^{3}$ Only two situations allow for discretionary recesses, if the prosecutor is not present (1-hour break) or in cases of extreme complexity (2 hours break) (DOF, 2014)
} 
The model finds significant, consistent, and economically relevant results for the effect of $N O_{x}$ on hearings' length. In the preferred specification, one standard deviation increase in $N O_{x}$ raises the time of judicial hearings by 1.55 minutes. This result translates to a shortterm shock of exposure to $N O_{x}$ of $3.68 \%$. To put this into context, one standard deviation increase in $N O_{x}$ is equivalent to the difference in the sample level of exposure at 6:00 a.m., when there is no traffic and the night has washed away most contaminants, and 8:00 a.m., when the concentration of $N O_{x}$ almost doubles, even more, at 10 a.m. the level of exposure increases by one additional standard deviation. If we aggregate the number of hearings happening at 10 a.m. across my sample period 2015-2017, we have 1,781 cases approximating 5,520 lostminutes or nearly four full days of missed labor because of the productivity shock stemming from the exposure difference between six and ten in the morning. The IV coefficients using wind direction, wind speed, and atmospheric pressure as instruments remain significant and show higher point estimates. Furthermore, the results also survive two different placebo tests: one, randomizing exposure across time and another interchanging the pollution values across monitoring stations.

The main contributions of this paper to the literature are: First, the study contributes to current research on the effects of pollutants on productivity by studying the impact of a new particle: nitrogen oxides. Second, it complements current studies by exploiting the temporal granularity of the data set and focusing on the very short-term (hourly) effect of exposure, and third, it takes care of a significant challenge to the identification of causality between air pollution and productivity, the impact of discretionary pauses.

The rest of the article is structured as follows; Section 2 provides a sum-up of relevant literature commencing with a general reminder of current articles connecting air pollution with human morbidity and mortality episodes. Afterward, I focus on evidence regarding how nitrogen oxides have negative effects on humans' health, and finally, I review studies examining the relationship between pollution, labor supply, and individual productivity. Section 3 develops a simple model to understand how the length of the hearing is a suitable proxy for the productivity of court participants and how the health consequences of exposure are the mechanism behind the drop in productivity. Section 4 describes the data set, its sources, and descriptive characteristics. Section Section 5 explains the econometric design and identification strategy used to infer causality. Section 6 provides the regression results of the econometric model. Section 7 runs additional specifications and placebo tests to increase the reliability of the study, 
and finally section 8 summarizes and concludes.

\section{Literature}

Research on the mechanisms through which pollution affects human beings tends to concentrate on the health and labor consequences of exposure. Regarding health, the formality and geographical heterogeneity of economic and epidemiological studies validate the general conclusion that exposure to airborne contaminants has negative consequences on the health of individuals. For example, Knittel et al. (2016) \& Jayachandran (2009) show that local pollution increases mortality. Rosales-Rueda and Triyana (2018) \& Bharadwaj et al. (2017) find that in-utero exposure affects long term health and sociodemographic outcomes. Halliday et al. (2018) \& Iskandar et al. (2012) suggests that pollution increases hospitalization rates. Ostro et al. (2001) points towards higher medicine intakes for asthmatic individuals and Moretti and Neidell (2011) show that air pollution increases the aggregate costs of health care services.

\subsection{Health and Nitrogen Oxides}

Air pollution is a combination of several different particles. In this study, I concentrate on one of them, nitrogen oxides. Several researchers have found evidence of their damaging impact of nitrogen oxides on respiratory health. Howden-Chapman et al. (2008), for instance, performs a randomized control trial on asthmatic children and find that improving the quality of household heaters (a known source of $\mathrm{NO}_{2}$ ) reduces wheeze, school absences, doctor visits, reports of poor health, and cough at night. Tunnicliffe et al. (1994) find that for $\mathrm{NO}_{2}$, increments from air-levels to 400 particles per billion (ppb) can affect the asthmatic airway response to house dust mite. Kaplan (2004) concludes that $\mathrm{NO}_{2}$ can increase the severity of asthma due to viral infections in the respiratory tract, and Hasselblad et al. (1992) perform a meta-analysis and finds evidence of a twenty percent increase on the probability of respiratory conditions in children exposed to $\mathrm{NO}_{2}$ during extensive periods of time. However, due to the reactive nature of $\mathrm{NO}_{x}$, it is not straightforward to understand their effect once they enter the organism. A couple of other studies question the validity of these previous findings by claiming that these studies may be measuring a surrogate contaminant of $N O_{x}$, and not $N O_{x}$ itself (Hesterberg et al., 2009, Sunyer et al., 2004, Brand et al., 2016). Moreover, it is not only the isolated effect of $N O_{x}$ what could trigger adverse responses, but also the complicated chemical behavior that allows them 
to bond and form new elements before inhalation and even after they enter the human body. Because of this, the epidemiological literature on their effect on the respiratory system is not entirely conclusive.

On the consequences of $N O_{x}$ on cognitive performance, we know little about the exact pathways by which $N O_{x}$ reaches the brain. However, animal studies have shown that environmental contaminants can use the upper respiratory system to enter the central nervous system (Oberdörster et al. 2004) and from there interact with brain activities. Schikowski et al. (2015) finds a significant impact of long term exposure to $N O_{x}$ on the cognitive performance of older women, and Ranft et al. (2009) finds the same effect for traffic pollution ( $N O_{x}, P M_{10}$, and $C O$ ) on a cohort of elderly adults. The complicated biochemical relation between $N O_{x}$ and the human body has even provided studies finding an impact of $N O_{x}$ exposure on multiple sclerosis relapses (Oikonen et al., 2003) and the prevalence of diabetes (Pitocco et al., 2010). However, even these results come without information on the exact pathways through which $N O_{x}$ affects neural activities.

It is this complicated relationship between $N O_{x}$ and the human body that does not allow me to show a definite medical reason behind the productivity shock. Still, in my opinion, the most likely candidates are neurotoxicity and respiratory morbidity. Neurotoxicity refers to an excess of $N O$ in the organism that can induce death in different types of neuronal cells (Wei et al., 2000) and lead to cognitive damage. Concerning respiratory morbidity, its adverse effects on the brain are likely to come from energy depletion or reductions in the supply of oxygen. In general, more conclusive epidemiological evidence is necessary to pinpoint the medical relationship between $N O_{x}$ and productivity to a single cause.

\subsection{Effects of Pollution on Labor Supply and Productivity}

Regarding the effects of air pollution on labor markets, current literature concentrates on labor absences or productivity at work. For labor absences, Hanna and Oliva (2015) exploit the closure of the Azcapozalco refinery in Mexico City to conclude that decreasing exposure to sulfur dioxide $\left(\mathrm{SO}_{2}\right)$ by $20 \%$ increases hourly labor supply by 3.5\%, Aragon et al. (2016) find similar effects for fine particle matter $\left(P M_{2.5}\right)$ in a Peruvian study, and Kim et al. (2017) for coarse particle matter $\left(P M_{10}\right)$ in Indonesia. On the effects of pollution on the brain, there is a battery of studies showing evidence of cognitive impairment. For example, Heyes et al. (2016) find that air pollution in the form of fine particle matter can affect the behavior of 
financial markets through a decrease in the value of the S\&P index and changes in the risk behavior of stock-traders. Additionally, Lavy et al. (2014) show that higher levels of exposure to fine particle matter and carbon monoxide reduce grades in standardized Israeli school tests, while Archsmith et al. (2018) analyze the quality of umpire decisions in conditions of varying exposure to carbon monoxide, they find that higher levels of $C O$ increase the probability of umpires making incorrect calls. All of these studies point to a negative effect of air pollutants on the brain.

When we analyze studies dealing with the effects of pollution on productivity at work, the number of articles is less extensive than for mortality, morbidity, well-being, or labor supply. The main reason is that it is challenging to collect suitable productivity proxies amid working hours. One option is to analyze activities with an easily accountable output as manufacturing or agriculture. Graff Zivin and Neidell (2012) investigate the impact of daily ozone $\left(\mathrm{O}_{3}\right)$ concentrations on the productivity of Californian farmers and find significant adverse effects. An increase of $10 \mathrm{ppb}$ in the atmospheric concentration of $\mathrm{O}_{3}$ leads to a $5.5 \%$ decrease in agricultural output. Chang et al. (2016) analyze the influence of daily exposure to $P M_{2.5}$ on the production of pear packers in the United States. They show that a 10 unit change in $P M_{2.5}$, decreases worker productivity by roughly $6 \%$. Overall, this article is mainly related to a new stream of literature on the relationship between air pollution and the productivity of whitecollar professions. To the best of my knowledge, only two other articles look at this effect. Chang et al. (2019) analyze the impact of local pollution in labor productivity for two call centers in Nantong and Shanghai. They conclude that there is an effect on the average time and the number of calls completed by call-center employees. A 10 unit increase in a self-constructed pollution index decreases the number of phone calls by $0.35 \%$. Unfortunately, they also point out that people taking longer breaks are responsible for the effect, and thus they cannot disentangle the in-work productivity shock from the impact of prolonged pauses. Meyer and Pagel (2017) find that German investors reduce labor supply and trading volume when exposed to high levels of $P M_{10}$. One standard deviation increase in $P M_{10}$ decreases the probability of logging into the trading platform by $8.5 \%$ and that even when logged in, the likelihood of trading is reduced by $1 \%$. This article contributes to this literature by analyzing the impact of a new contaminant, over a new time window, and for a new profession while explicitly controlling for breaks while working. 


\section{Background on Productivity}

Productivity is a measure of output per invested units of input while holding quality constant; $p=\frac{\text { Output }}{\text { Input }} \mid Q$. In this mathematical representation, $Q$ depicts quality and $p$ productivity. For an agricultural worker, this will be equivalent to the number of crops harvested per unit of time (taking into consideration that the quality of the harvesting remains constant). For hearing participants, however, the only output is the hearing itself and the input the collective effort (work) of all involved participants. I approximate this effort by invested person-hours in the hearing process. As such, the productivity of each hearing decomposes to $p=\frac{\text { hearing }=1}{\text { time }} \mid Q$. The less time it takes hearing participants to finish the trial, the more productive they are. Because of this simple insight, I approximate their productivity with the length of the process according to equation 1 .

$$
\tau=f[\gamma, X, \omega, Y, H=f(\rho)]
$$

Where $\tau=p^{-1}$ represents the length of the hearing in seconds, $\gamma$ contains all of the time constant individual variables at the courthouse and judge level that could influence the time of the process. $X$ is a battery of hearing specific characteristics that also influence its length like the type of crime or the final resolution. $\omega$ captures all variables that change at particular time windows with a matrix of temporal controls. $Y$ is a matrix of additional variables as other contaminants or weather events that could affect both productivity and the level of $N O_{x}$. Finally, $H=f(\rho)$ is a measure of health that depends on the level of exposure to $N O_{x}$. This article proposes that the first derivative of this equation concerning $\rho$ will be positive; $\frac{\partial \tau}{\partial H} \frac{d H}{d \rho}>0$, and thus nitrogen oxides would increase the length of the hearing, and by the relationship, $\tau=p^{-1}$, decrease the productivity of participating individuals. The assumption that $\frac{\partial \tau}{\partial H} \frac{d H}{d \rho}>0$ is supported by the previously mentioned health effects of exposure to $N O_{x}$, for example, decreased lung function, higher allergen sensitivity, and neurotoxicity. Unfortunately, disentangling the exact epidemiological mechanism is not possible because of the compound effect of $N O_{x}$ and lack of epidemiological certainty.

A potential caveat of the study is that I cannot control for the quality of the resolution $Q$. It is possible that air pollution changes the length of the hearing through its effect on hearings' quality and not through its impact on productivity. It is important to remember the 
strict difference between quality and productivity, as some articles in the literature use the terms interchangeably, productivity is a measure of output per invested unit of input while holding quality constant. In contrast, quality is a standard that needs to be compared against similar output units. Unfortunately, I have no way to assess the quality of the judge's ruling. However, I argue that even if the quality affects the length of the hearing, this would not change my conclusions because of two reasons. First, if pollution decreases quality, lower quality would likely decrease hearings' length and work against my hypothesis of increased hearing times. In this case, the results could be seen as lower bounds. Second, there is no reason to believe that exposure will improve quality, nor that decrements in the quality would increase the length of the process. Nonetheless, even if lower-quality trials take longer, the results from this study would show the aggregate effect of exposure, both from the consequences of lower quality and from the drop in labor productivity.

\section{Data}

\subsection{Court Hearings}

In Mexico, hearing times became available after the introduction of a country-wide judiciary reform that, among its many changes, required the precise measurement of hearings' length at each judicial process. Each process begins at the exact time all parties are present, and the judge initiates it. The trail ends at the moment of the resolution. Under Mexican law, citizens have the right to request any public information they require under the condition that the requested data exists (DOF, 2017). I use this tool to ask for the exact length of each judicial hearing, the id of the judge preceding it, the crime, hearing type, and final resolution 4

The federal structure of the country and its judiciary implies that states have specific penal codes with different definitions and classifications for crimes, trials, and resolutions. As a consequence, I sent information requests to the judicial systems of the states with the three most populated cities in the country: Mexico City, Guadalajara, and Monterrey ${ }^{5}$ Only Mexico City and Monterrey had available data. The dataset contains to-the-second data between Jan-

\footnotetext{
${ }^{4}$ Cititizens can request public information under https://www.plataformadetransparencia.org.mx/ web/guest/inicio

${ }^{5}$ I concentrate only on these cities because of the complexity and uncertainty behind the information request process. The type of information and data availability entirely depend on each state's data collection regulations and bureaucratic organization.
} 
uary 2015 and December 2017 of initial hearings happening in courthouses across both cities. Specifically, it includes the geographical coordinates of the courthouse hosting the hearing, individual judge identifiers, time identifiers for the beginning and the end of the process, crime typologies, type of trials (only for Monterrey), and final resolutions. Unfortunately, Mexico City only provided data on voluntary presence trials; thus, the data set is smaller and of lower quality than for Monterrey 6

Moreover, because of regional heterogeneity in the classification of crimes, I standardize them under the legal umbrella of the Mexican classification of offenses, according to the Mexican National Institute of Geography and Statistics (INEGI, 2014). There are a total of 30 different categories integrating 488 distinct felonies. Additionally, I classify resolutions and hearing types. Resolutions have eight different categories: warrants, authorized processes, nonAuthorized Processes, illegal Detentions, conditional exits, rescheduled hearings, and unavailable sentences - Hearings have four: unattended hearings, in flagrante processes, voluntary presence trails, and preventive jail.

\subsection{Air Pollution}

Concerning the causal variable, the National Institute of Climate Change (INECC) and the National Water Commission (CONAGUA) use city-wide monitoring stations to provide hourly data on weather and pollution measures. The studied pollutant is $N O_{x}$ shorthand for all chemical particles containing one nitrogen atom and one or more oxygen atoms. In the analysis of air pollution, it denotes the total concentration of nitrogen oxide $(\mathrm{NO})$ and nitrogen dioxide $\left(\mathrm{NO}_{2}\right)$ in the atmosphere. $N O_{x}$ contributes to the formation of smog and develops from the combustion of hydrocarbons at high temperatures, i.e., in internal combustion engines and fossil fuel power stations. Nitrogen oxides are in their majority emitted as $\mathrm{NO}$, while $\mathrm{NO}_{2}$ forms by the rapid interaction of $\mathrm{NO}$ with $\mathrm{O}_{3}$ and other radicals. In regions with considerable traffic problems, $N O_{x}$ can play a leading role as a source of air pollution.

It is essential to understand that anthropogenic emissions do not purely determine the level of nitrogen oxides in the atmosphere, the chemistry behind their concentration is highly complicated since they combine in several different ways with other chemical compounds. Image 1 shows a simplified version of the chemical reactions of $N O_{x}$ in an urban environment.

\footnotetext{
${ }^{6}$ There are three additional types of trials: unattended, in flagrante, and preventive. Furthermore, Mexico City provided administrative datasets while Monterrey has publicly accessible data at https://www.pjenl.gob. $\mathrm{mx} /$ AudienciasOrales/.
} 
First, the emissions of $\mathrm{NO}_{2}$ and $\mathrm{NO}$ can combine with volatile organic compounds (VOC) and sunlight to create hydroxide $(\mathrm{OH})$, which in turn, can mix with water and form ozone. Ozone can also combine with $\mathrm{NO}$ to create $\mathrm{NO}_{2}$, which by combination with other radicals as $\mathrm{OH}$ or ammonia $\left(\mathrm{NH}_{3}\right)$, could form deposition particles and decrease the level of $\mathrm{NO}_{x}$ in the atmosphere.

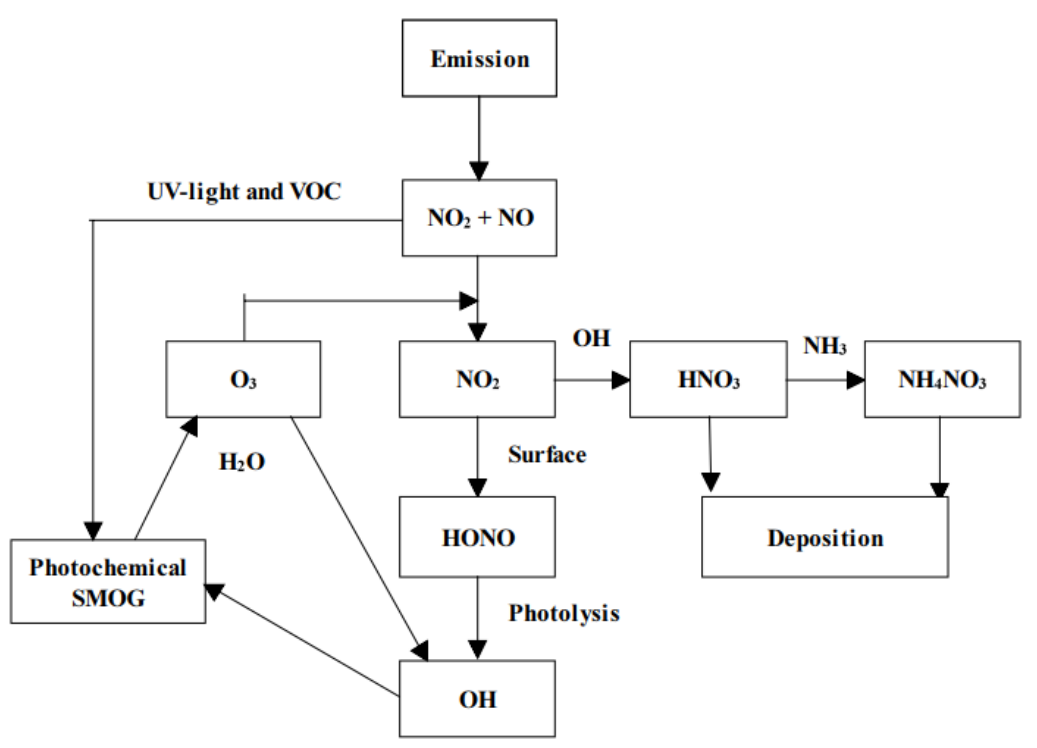

Figure 1: The nitrogen cycle in an urban environment

Notes: This image is a simplified schema of the complicated atmospheric behavior of nitrogen oxides. The picture was taken from the position paper on air quality: nitrogen oxides published in 1997 by a working group of the European Union (Lovbland et al. 1997).

However, despite this complicated chemical behavior, it suffices to understand that human activities are a constant source of these particles and that their concentration is higher in urban environments with higher levels of fossil-fuel consumption. Another factor to consider is the different level of exposure between indoors and outdoors, in principle, I have no way to now the level of $N O_{x}$ inside the courthouse, yet, previous assessments point to a range between $30 \%$ and $100 \%$ (Lovbland et al., 1997).

INECC also provides readings in micrograms per cubic meter $\left(\mu \mathrm{m}^{3}\right)$ for coarse and fine particle matter, in particles per billion for sulfur dioxide and ozone, and particles per million for carbon monoxide. Weather covariates are temperature, relative humidity, wind direction, wind speed, and atmospheric pressure. There are 36 different monitoring stations in Mexico City and its metropolitan area and 10 in the metropolitan area of the city of Monterrey. Figure 2 (a) shows the monthly concentration of $\mathrm{NO}_{x}, \mathrm{NO}$, and $\mathrm{NO}_{2}$ during the study period and figure 2 (b) plots their intraday behavior. All particles present higher concentrations at cold winter temperatures and peak traffic hours of the mornings and evenings. As the picture 
shows, the variation in the concentration of $N O_{x}$ is quite substantial. Between six and ten in the morning, the level of exposure almost triples, only to go back down in the afternoon because of the formation and interaction of $N O_{x}$ with other chemical compounds, this extreme intra-hour variation is a key element of my identification strategy.

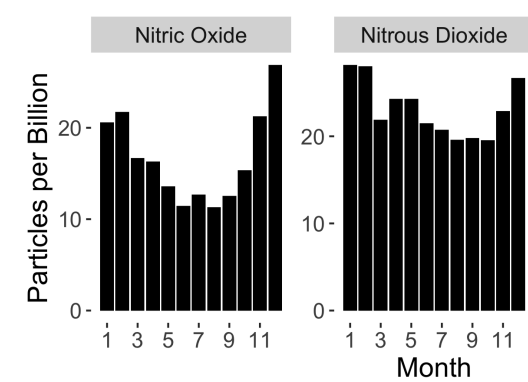

(a) Monthly variation

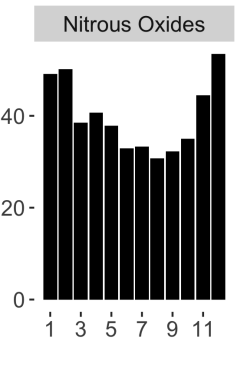

(b) Hourly variation

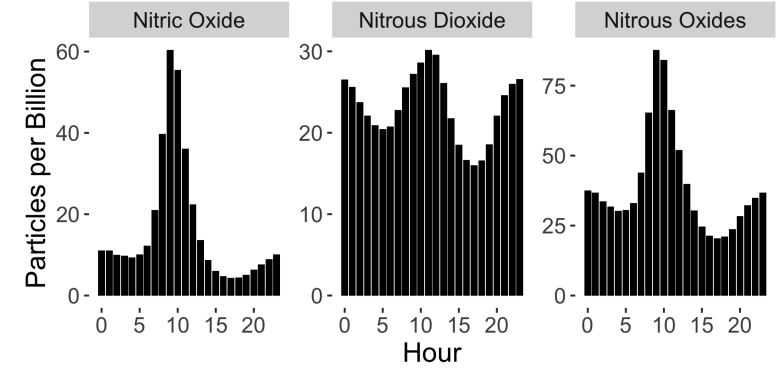

Figure 2: Temporal behavior of $\mathrm{NO}_{x}, \mathrm{NO}$, and $\mathrm{NO}_{2}$

Notes: These figures use averaged data from monitoring stations to show the temporal variation in exposure values across the sample

I assign pollution levels to individual courthouses through inverse distance weighting (IDW). IDW is a spatial interpolation tool that approximates the value of a point in the spatialset by weighting the concentration levels of comparable neighbors (Shepard, 1968). Several studies addressing pollution employ IDW to interpolate the value of specific reference points, or to determine the pollution values of whole areas (De Mesnard, 2013).7 Table 1 shows basic descriptive statistics for all three contaminants and two different subsamples. The upper section shows descriptive statistics for all monitoring stations, while the lower shows the descriptive statistics of imputed courthouse values. The table exhibits that on average, courthouses experience lower levels of $N O_{x}$ pollution than monitoring stations.

Finally, city-wide macroeconomic data comes from the Mexican Institute for Competitiveness (IMCO). Macroeconomic data is important as it may influence hearings' length and correlate with local pollution; i.e., gross domestic product as a proxy for economic activity commonly associates with the emission of local contaminants and it is also a determinant of poverty and crime through its income-employment effect. A caveat of the macroeconomic data is that it is only available for 2014. To impute the values for 2015, 2016, and 2017, I use state

\footnotetext{
${ }^{7}$ The following equation is the mathematical representation of such interpolation. The power factor $p$ modifies the heaviness of the weighing load for each monitoring station. The higher $p$, the larger the weight of closer stations. This paper uses a weight of two as recommended by De Mesnard (2013) for air pollution.

$$
V\left(\text { pol }_{j t}\right)=\left\{\begin{array}{c}
\frac{\Sigma_{i}^{N} \omega\left(\text { dist }_{i}\right) * p o l_{i t}}{\sum_{i}^{N} \omega\left(\text { dist }_{i j}\right)} \\
p o l_{i t} \rightarrow \text { dist }_{i j}=0
\end{array}\right\} \Longrightarrow \omega\left(\text { dist }_{i j}\right)=\frac{1}{\operatorname{distance}\left(x_{i}, x_{j}\right)^{p}}
$$

$V\left(p_{j t}\right)$ is the weighted value of pollution at point $\mathrm{j}$ and time $\mathrm{t}$, pol $_{i t}$ refers to the value of pollution in station $i$ at time $t$, and $d_{i s t_{i j}}$ is the distance between each courthouse and each station.
} 
Table 1: Summary Statistics of the Data Set

\begin{tabular}{ccccc}
\hline Pollutant & Mean & Standard Deviation & Maxima & Minima \\
\cline { 2 - 5 } & \multicolumn{4}{c}{ Sample: All monitoring stations } \\
Nitrogen Oxides & 39.690 & 37.915 & 755 & 0 \\
Nitrogen Oxide & 16.417 & 29.618 & 688 & 0 \\
Nitrogen Dioxide & 23.277 & 14.122 & 150 & 0 \\
\hline & \multicolumn{5}{c}{ Sample: Weighted values at courthouses } \\
\cline { 2 - 5 } & \multicolumn{5}{c}{0.116} \\
Nitrogen Oxides & 5.048 & 6.658 & 193.75 & 0.16 \\
Nitrogen Dioxide & 2.425 & 2.618 & 38.00 & 0.080 \\
Nitrogen Oxide & 2.426 & 4.604 & 755 & 0.023 \\
\hline
\end{tabular}

Table notes: All values are in particles per billion. This table shows the descriptive statistics of two different samples. The upper section shows the descriptive statistics across all monitoring stations in both cities. The lower section does it for the imputed values at each courthouse. Courthouse values were imputed with Inverse Distance Weighting

and national growth rates 8 The macroeconomic controls are GDP, poverty rates, unemployment, and the number of inhabitants.

\section{Research Design}

\subsection{Identification}

The regression design identifies the effect of nitrogen oxides on the length of judicial hearings by using the spatial and temporal variation of exposure values across all courthouses and throughout the whole sample period. Judge and courthouse fixed effects account for all unobservable time-invariant covariates that can correlate with both exposure to nitrogen oxides and hearings' length. Time fixed-effects control for all unobserved consistent time-varying unobservables by specifying year, month, weekday, and hour fixed effects. Additionally, the design also accounts for a broad set of controls as hearing characteristics, workloads, weather, and macroeconomic variables. Furthermore, since exposure to nitrogen oxides is not randomly assigned, it is impossible to rule out the existence of uncontrolled time-varying correlated unobservables. To deal with this caveat, I complement the econometric strategy with an instrumental variable approach that relies on wind direction, wind speed, and atmospheric pressure as ex-

\footnotetext{
${ }^{8}$ For gross domestic product, there is state data for 2015 and 2016, but only national data for 2017. The imputation mechanism uses the state growth rates for 2015 and 2016 to calculate the missing values for these years. Concerning 2017, the percentage rate of each state's GDP as a function of national GDP in 2016 is used to extract the state GDP for 2017, and with this figure determining the growth rate between 2016 and 2017. For the population, the design assumes a linear growth rate, where the value for 2015 comes from the growth rate in 2014 multiplied by the value for 2014. The same process applies for 2016 and 2017. For poverty rates, the national council for the evaluation of policies and public development only determines state poverty rates in two-year averages. The imputation design uses the average growth rate between the years 2010, 2012, 2014, and 2016 to impute $2015-2017$ city poverty rates.
} 
ogenous shocks to the concentration of nitrogen oxides. The IV design relies on the assumption that the instruments only affect the productivity of hearing participants through their effect on the level of nitrogen oxides.

Identification requires exogeneity of the causal variable when controlling for potential confounders. Exogeneity originates from the amount of control data, the use of panel techniques, the time granularity of the causal and dependent variables, the specificity of the effect, and the implementation of the IV design. Another requirement is that the type of hearing must be random and uncorrelated to pollution levels. The Mexican judiciary uses workloads and specialization to distribute cases among courthouses. In principle, there should not be specific crimes assigned at specific hours.9 9 An additional worry is that the state judiciary can require judges to rule in other locations besides their base courthouse. I control for this heterogeneity by using both, courthouse and judge fixed effects. Finally, endogenous sorting of exposure, where more sensitive persons work in less exposed courthouses, is unlikely because hearing participants do not choose the courthouse of the trial; the state's judiciary centrally assigns them.

To ensure identification, I only include procedures with lengths of less than four hours. There are several reasons for this: First, proceedings that continue for more than four hours are considered outliers or unconventional trials. Second, the degree of exposure to pollution throughout the hearing is more difficult to identify. Third, when trials last for more than four hours, hearing participants can have short breaks causing noise in the identification of in-work productivity as it is not possible to disentangle real shocks to in-work productivity from longer breaks. Dropping these lengthy procedures reduces the sample size by $2.2 \%$. Finally, I account for the within-cluster correlation of standard errors by using cluster-robust variance estimators at the courthouse level.

\subsection{Empirical Model}

The design uses panel techniques and a broad set of controls to infer the causal relationship between exposure to nitrogen oxides and the length of judicial hearings. Equation 2 shows the primary econometric model for the ordinary least squares regression (OLS).

\footnotetext{
${ }^{9}$ Although some crimes may be more likely at the night time, this does not affect the econometric specification because of the use of hour fixed effects.
} 


$$
Y_{i}=P_{i} \beta_{1}+H_{i} \gamma+C_{i} \phi+W_{i} \lambda+\omega_{h}+\omega_{d}+\omega_{m}+\omega_{y}+\mu_{c}+\mu_{i}+\varepsilon_{i}
$$

In it, $Y_{i}$ is a $(\mathrm{t} \times 1)$ vector of individual hearing lengths. $P_{i}$ is a $(\mathrm{t} \times 1)$ vector of exposure to $N O_{x}$ at the hour in which the hearing begins. $H_{i}$ is a $(\mathrm{t} \times \mathrm{k})$ matrix with $\mathrm{t}$ periods and $\mathrm{k}$ hearingrelated variables. $C_{i}$ is a $(\mathrm{t} \times \mathrm{m})$ matrix of $m$ macroeconomic variables at the city level. $W_{i}$ is an $(\mathrm{t} \times \mathrm{w})$ matrix of $w$ weather variables and when necessary, additional pollutants that allow the design to test for spurious correlation with the use of multipollutant models. $\omega_{h}$ are hour fixed effects, $\omega_{d}$ day of the week fixed effects, $\omega_{m}$ month fixed effects, $\omega_{y}$ year fixed effects, $\mu_{c}$ courthouse fixed effects, and $\mu_{i}$ judge fixed effects. Finally, $\varepsilon_{i}$ is a vector of idiosyncratic error terms. The pollution coefficient $\beta_{1}$ indicates the effect of nitrogen oxides on the length of judicial hearings, and according to $\frac{\partial \tau}{\partial H} \frac{d H}{d \rho}>0$, I expect it to be positive and significant.

Moreover, I control for possible uncontrolled time-varying unobservables by implementing an instrumental variable regression design with wind direction, wind speed, and atmospheric pressure as instruments. Equation 3 shows the first stage regression of nitrogen oxides $\hat{p}_{i}$ on all the covariates of the OLS specification plus a $(\mathrm{t} \times \mathrm{k})$ matrix of $k$ instrumental variables $\left(I V_{i}\right)$. Equation 4 exhibits the second stage regression using the fitted values $\hat{p}_{i}$ from equation 3 as the causal variable.

$$
\begin{aligned}
& \hat{P}_{i}=I V_{i} \rho+H_{i} \gamma+C_{i} \phi+W_{i} \lambda+\omega_{h}+\omega_{d}+\omega_{m}+\omega_{y}+\mu_{c}+\mu_{i}+\hat{\varepsilon}_{i} \\
& Y_{i}=\hat{P}_{i} \beta_{2}+H_{i} \gamma+C_{i} \phi+W_{i} \lambda+\omega_{h}+\omega_{d}+\omega_{m}+\omega_{y}+\mu_{c}+\mu_{i}+\varepsilon_{i}
\end{aligned}
$$

\section{Main Results}

\subsection{Ordinary Least Squares}

Table 2 shows the results of five different specifications for the ordinary least squares regression. The specifications build up from a single pollutant model that only controls for $N O_{x}$ to a full multipollutant model controlling for workloads, hearing covariates, macroeconomic variables, and weather controls. All regressions contain workloads, judge and courthouse indi- 
vidual fixed effects plus year, month, weekday, and hour temporal fixed effects. The coefficient for nitrogen oxides shows the causal effect of exposure on the proxy for productivity: the time it takes for judicial workers to reach a hearing resolution.

Table 2: Regressions results for nitrogen oxides

\begin{tabular}{|c|c|c|c|c|c|}
\hline & \multicolumn{5}{|c|}{ Dependent variable: Hearings' length } \\
\hline & $(1)$ & $(2)$ & (3) & (4) & $(5)$ \\
\hline \multirow[t]{2}{*}{ Nitrogen Oxides $\left(N O_{x}\right)$} & 0.048 & $0.251^{* *}$ & $0.233^{* *}$ & $0.233^{* *}$ & $0.280^{* *}$ \\
\hline & $(0.081)$ & $(0.084)$ & $(0.073)$ & $(0.073)$ & $(0.104)$ \\
\hline \multirow[t]{2}{*}{ Hearings per Day } & $-0.160^{*}$ & -0.115 & -0.101 & -0.101 & -0.076 \\
\hline & $(0.071)$ & $(0.071)$ & $(0.071)$ & $(0.071)$ & $(0.072)$ \\
\hline \multirow[t]{2}{*}{ Hearings per Hour } & $1.151^{* * *}$ & $1.228^{* * *}$ & $1.445^{* * *}$ & $1.445^{* * *}$ & $1.634^{* * *}$ \\
\hline & $(0.148)$ & $(0.181)$ & $(0.200)$ & $(0.200)$ & $(0.183)$ \\
\hline Authorized Resolution & & $\begin{array}{c}19.691^{* * *} \\
(2.351)\end{array}$ & $\begin{array}{c}19.687^{* * *} \\
(2.347)\end{array}$ & $\begin{array}{c}19.687^{* * * *} \\
(2.347)\end{array}$ & $\begin{array}{c}18.968^{* * *} \\
(2.517)\end{array}$ \\
\hline \multirow[t]{2}{*}{ Warrant Resolution } & & $9.145^{* * *}$ & $8.982^{* * *}$ & $8.982^{* * *}$ & $9.739^{* * *}$ \\
\hline & & $\begin{aligned} & (2.263) \\
- & 23.042^{* * *}\end{aligned}$ & $\begin{aligned} & (2.259) \\
- & 23.040^{* * *}\end{aligned}$ & $\begin{aligned} & (2.259) \\
- & 23.040^{* * *}\end{aligned}$ & $\begin{aligned} & (2.469) \\
- & 22.944^{* * *}\end{aligned}$ \\
\hline Unattended Hearing & & $(1.997)$ & $(1.996)$ & $(1.996)$ & $(2.064)$ \\
\hline Life Crime & & $10.955^{* * *}$ & $10.984^{* * *}$ & $10.984^{* * *}$ & $11.431^{* * * *}$ \\
\hline \multirow[t]{2}{*}{ Sexual Crime } & & $9.210^{* * *}$ & $9.221^{* * *}$ & $9.221^{* * *}$ & $9.286^{* * *}$ \\
\hline & & $(1.660)$ & $(1.656)$ & $(1.656)$ & $(1.741)$ \\
\hline Relative Humidity & & & 0.096 & 0.096 & $\begin{array}{l}0.147 \\
(0.097)\end{array}$ \\
\hline \multirow[t]{2}{*}{ Temperature } & & & $0.311^{+}$ & $0.311^{+}$ & -0.007 \\
\hline & & & $(0.168)$ & $(0.168)$ & $(0.380)$ \\
\hline GDP & & & & $-0.068^{*}$ & $-0.066^{+}$ \\
\hline \multirow{2}{*}{ Particle Matter $\left(P M_{10}\right)$} & & & & $(0.035)$ & $\begin{array}{l}(0.035) \\
-0.005\end{array}$ \\
\hline & & & & & $(0.053)$ \\
\hline Sulfur Dioxide $\left(\mathrm{SO}_{2}\right)$ & & & & & -0.013 \\
\hline \multirow[t]{2}{*}{ Carbon Monoxide $(\mathrm{CO})$} & & & & & $\begin{array}{l}(0.500) \\
4.808\end{array}$ \\
\hline & & & & & $(6.861)$ \\
\hline Ozone $\left(\mathrm{O}_{3}\right)$ & & & & & $\begin{array}{c}0.196 \\
(0.162)\end{array}$ \\
\hline R-squared & 0.078 & 0.244 & 0.244 & 0.244 & 0.248 \\
\hline No. Obs. & 11290 & 11290 & 11289 & 11289 & 10961 \\
\hline
\end{tabular}

Table notes: ${ }^{* * *} p<0.001,{ }^{* *} p<0.01,{ }^{*} p<0.05,{ }^{+} p<0.1$. OLS regressions of the length of each judicial hearing on exposure to nitrogen oxides at the hour of the hearing. All regressions contain courthouse, judge, year, month, weekday, and hour fixed effects. Specification (1) contains nitrogen oxides and fixed effects. The other specifications add further controls while always keeping the covariates from the previous specification: (2) adds hearing specific covariates as the type of crime, the final resolution, and the hearing class; (3) adds weather covariates like temperature, and relative humidity; (4) adds macroeconomic covariates at the city level; (5) adds additional measured pollutants. The reference crime is property crimes, reference hearing unattended hearing, and reference resolution Rescheduled cases — robust standard errors clustered at the judge level in parentheses.

The impact of exposure is positive, significant, economically relevant, and consistent across specifications. In the richest single-pollutant model, a unit increase in its concentration raises the length of trials by 0.233 units at the one percent significance level. In broader terms, growing the concentration of $N O_{x}$ by one raises the mean length of judicial hearings $(42.12$ minutes) by 12 seconds or half a percentage point. Concerning standard deviations, one standard deviation increase rises the length by 1.55 minutes or $3.68 \%$. When the model includes 
all other pollutants $\left(\mathrm{PM}_{10}, \mathrm{SO}_{2}, \mathrm{CO}, \mathrm{O}_{3}\right)$, the coefficient remains significant at the one percent level and grows in size to 0.280 . This multipollutant outcome shows no significant point estimate among all other contaminants and indicates no clear spurious correlation between $N O_{x}$ and the other particles.

Regarding additional covariates, authorized resolutions and warrants exhibit a significant and positive effect on resolution times when compared with rescheduled procedings. Unattended hearings show lower resolution times than in flagrante cases, and sexual or lifethreatening crimes increase the length of judicial hearings when compared to property offenses; all these coefficients follow pure intuition and reinforce the results of the $N O_{x}$ estimate.

Table 3 show the same results for $\mathrm{NO}_{2}$ and $\mathrm{NO}$. Both $\mathrm{NO}$ and $\mathrm{NO}_{2}$ appear significant for the tightest specification of the single pollutant model (4). The model exhibits a coefficient of 0.256 for $\mathrm{NO}$ and 0.355 for $\mathrm{NO}_{2}$. With respect to $\mathrm{NO}$, an increase of one standard deviation in its mean-average concentration increases trial's length by 1.06 minutes or by $2.52 \%$, in the multipollutant model, the coefficient grows in both significance and size. For $\mathrm{NO}_{2}$, one standard deviation increase rises the length of hearings by 0.83 minutes or $2.0 \%$. However, for $\mathrm{NO}_{2}$, the significance disappears on the multipollutant model. When testing which pollutant is responsible, it appears that $\mathrm{CO}$ reduces the significance level of $\mathrm{NO}_{2}$ due to multicollinearity.

Table 3: Regressions results for all nitrogen oxides components in the IV design

\begin{tabular}{lccccc}
\hline & \multicolumn{5}{c}{ Dependent variable: Hearings, length } \\
\cline { 2 - 6 } & $(1)$ & $(2)$ & $(3)$ & $(4)$ & $(5)$ \\
\hline Nitrogen Oxides $\left(N O_{x}\right)$ & 0.020 & $0.196^{*}$ & $0.203^{* *}$ & $0.203^{* *}$ & $0.275^{* *}$ \\
Nitrogen Oxide $(N O)$ & $(0.074)$ & $(0.077)$ & $(0.077)$ & $(0.077)$ & $(0.106)$ \\
Nitrogen Dioxides $\left(N O_{2}\right)$ & 0.041 & $0.252^{* *}$ & $0.256^{* *}$ & $0.256^{* *}$ & $0.348^{* * *}$ \\
& $(0.096)$ & $(0.088)$ & $(0.085)$ & $(0.085)$ & $(0.080)$ \\
& 0.027 & $0.341^{*}$ & $0.355^{*}$ & $0.355^{*}$ & 0.281 \\
No. Obs. & $0.186)$ & $(0.150)$ & $(0.148)$ & $(0.148)$ & $(0.286)$ \\
\hline
\end{tabular}

Table notes: ${ }^{* * *} p<0.001,{ }^{* *} p<0.01,{ }^{*} p<0.05,{ }^{+} p<0.1$. OLS regressions of the length of each judicial hearing on exposure to nitrogen oxides, Nitrogen oxide, and Nitrogen dioxide at the hour of the hearing. All regressions contain judge, courthouse, year, month, weekday, and hour fixed effects. Specification (1) contains the contaminant and fixed effects. The other specifications add further controls while always keeping the covariates from the previous specification: (2) adds hearing specific covariates as the type of crime, the final resolution, and the type of hearing; (3) adds weather covariates like temperature and relative humidity; (4) adds macroeconomic covariates at the city level; (5) adds additional measured pollutants. Robust standard errors clustered at the judge in parentheses.

\subsection{Instrumental Variables}

The temporal granularity and spatial heterogeneity of the fixed effects OLS regression should provide credible estimates of the short-term negative relation between hearings' length and 
nitrogen oxides. However, I instrument the level of nitrogen oxides to correct for potential complications as measurement error, endogeneity, and omitted variable bias from uncontrolled covariates like traffic. I propose wind direction, wind speed, and atmospheric pressure as relevant instruments under the assumption that these covariates only affect the length of each hearing through their influence on the concentration of $N O_{x}$. Wind direction increases exposure when the wind flows from emission sources to the courthouse, wind speed because high speeds disperse contaminants and atmospheric pressure because, during low-pressure systems, the weather tends to washout contaminants from the atmosphere.

A good instrument needs to be a significant covariate of the causal variable. In this case, wind direction, wind speed, and atmospheric pressure need to be relevant determinants of $N O_{x}$. The Wald test examines the relevance of the instrument by comparing two models: the first stage equation where nitrogen oxides regress on relevant covariates plus all three instruments (Eq. 3), and the same equation without the set of instrumental controls. Table 4 show the results of the Wald test for $\mathrm{NO}_{x}, \mathrm{NO}$, and $\mathrm{NO}_{2}$. For all three particles, the Wald test rejects the null hypothesis of instruments irrelevance.

Table 4: Wald test for instrument validity

Instruments: Wdr, Wsp, and PBa

\begin{tabular}{lccc} 
Pollutant & P-value & $\chi^{2}$ statistic & Diff. DF \\
\hline Nitrogen Oxides $\left(N O_{x}\right)$ & $2.2 \mathrm{e}-16^{* * *}$ & 90.574 & -3 \\
Nitrogen Oxide $(N O)$ & $8.1 \mathrm{e}-13^{* * *}$ & 59.340 & -3 \\
Nitrogen Dioxide $\left(N O_{2}\right)$ & $2.2 \mathrm{e}-16^{* * *}$ & 1138.9 & -3 \\
\hline
\end{tabular}

Table notes: ${ }^{* * *} p<0.001,{ }^{* *} p<0.01,{ }^{*} p<0.05,{ }^{+} p<0.1$. Wdr: wind direction; Wsp: wind speed; and PBa: atmospheric pressure. Wald tests to analyze the validity of wind direction, wind speed, and atmospheric pressure as instruments. If significant, the Wald test rejects the null hypothesis of instrument irrelevance. The test compares two models Eq. 3 and the same equation 3 without the instruments' matrix

Once there is certainty about the validity of the instruments, they can be used to test for the endogeneity of the causal variable: $\operatorname{cor}\left(p_{i}, \varepsilon_{i}\right) \neq 0$. The preferred test to check for endogeneity is the Hausman test. The test examines endogeneity by using the residuals from the first stage regression (Eq. 3) as an additional covariate to the base design. If the residuals from this equation $\left(\hat{\varepsilon}_{i}\right)$ are significant, the test confirms the null hypothesis of an endogenous relation between the causal variable and the model. Table 5 shows the outcomes of the Hausman test. For all three particles, the test confirms the null at the one and five percent levels of significance signaling endogeneity problems.

Table 6 show the coefficients of the instrumental variable regressions with wind speed, wind direction, and atmospheric pressure as instruments. All point estimates remain significant 
Instruments: Wdr, Wsp, and PBa

\begin{tabular}{lccc} 
Pollutant & P-value & $\chi^{2}$ statistic & Diff. DF \\
\hline Nitrogen Oxides $\left(\mathrm{NO}_{x}\right)$ & $0.01418^{*}$ & 5.9659 & -3 \\
Nitrogen Oxide $(\mathrm{NO})$ & $0.0023^{* *}$ & 9.2341 & -3 \\
Nitrogen Dioxide $\left(\mathrm{NO}_{2}\right)$ & $0.03468^{*}$ & 4.46095 & -3 \\
\hline
\end{tabular}

Table notes: ${ }^{* * *} p<0.001,{ }^{* *} p<0.01,{ }^{*} p<0.05,{ }^{+} p<0.1$. Wdr: wind direction; Wsp: wind speed; and PBa: atmospheric pressure. Haussman tests to analyze the exogeneity of the causal variable. If significant, the Wald test rejects the null hypothesis of exogeneity.

and increase in size with respect to the OLS design. The fullest single pollutant model (4) exhibits a point estimate of 0.274 significant at the one percent level while the multipollutant model (5) grows the size of the estimate to .291 while remaining significant at the five percent level. For the fullest single pollutant model, increasing the concentration of nitrogen oxides by one standard deviation raises the length of judicial hearings by 1.90 minutes or $5.89 \%$. Concerning the multipollutant model, the effect is of 2.02 minutes or $6.07 \%$.

Analogous to section 6.1, table 7 shows the results of $N O_{x}$ and its two composite particles $\mathrm{NO}$ and $\mathrm{NO}_{2}$. For $\mathrm{NO}$, the point estimate grows in both size and significance. In the single pollutant model (4), increasing its concentration by one standard deviation rises hearings' length by $6.02 \%$. For $\mathrm{NO}_{2}$ the point estimates remain quite similar although overall insignificant. The results from the IV design point in the same direction than the outcomes of the ordinary least squares regressions: increasing the concentration of $N O_{x}$ rises the length of judicial hearings. The consistency of outcomes between specifications increases the reliability of the econometric design and points toward an acute short-term impact of $N O_{x}$ on hearings' length.

The size of the effect $-3.68 \%$ for OLS and $5.8 \%$ for IV - appears in line with current literature on the effect of other criteria pollutants on physical and cognitive productivity. Graff Zivin and Neidell (2012) find that a $10 \mathrm{ppb}$ increment in exposure to ozone decreases agricultural output by 5.5\%, while Chang et al. (2016) find that the same change in $P M_{2.5}$ decreases the output of pear packers by $6 \%$. For cognitive productivity, Chang et al. (2019) find that a ten units increase in a self-constructed pollution index decreases the number of completed calls in Chinese call centers by $0.35 \%$. Meyer and Pagel (2017) find that one standard deviation increase in $P M_{10}$ decreases the probability of stock traders logging into their working platform by $8.5 \%$ and that even when logged in, the likelihood of trading is reduced by $1 \%$. However, it is still hard to make blunt comparisons given that this is, to the best of my knowledge, the first study examining the effects of nitrogen oxides on productivity, the first to analyze the 


\begin{tabular}{|c|c|c|c|c|c|}
\hline & \multicolumn{5}{|c|}{ Dependent variable: Hearings' length } \\
\hline & (1) & $(2)$ & (3) & (4) & $(5)$ \\
\hline Nitrogen Oxides $\left(N O_{x}\right)$ & 0.122 & $\begin{array}{l}0.336^{* *} \\
(0.108)\end{array}$ & $\begin{array}{l}0.274^{* *} \\
(0.105)\end{array}$ & $\begin{array}{l}0.274^{* *} \\
(0.105)\end{array}$ & $\begin{array}{l}0.291^{*} \\
(0.116)\end{array}$ \\
\hline Hearings per Day & $\begin{array}{l}-0.085 \\
(0.077)\end{array}$ & $\begin{array}{c}-0.143^{+} \\
(0.075)\end{array}$ & $\begin{array}{l}-0.116 \\
(0.075)\end{array}$ & $\begin{array}{l}-0.116 \\
(0.075)\end{array}$ & $\begin{array}{l}-0.113 \\
(0.075)\end{array}$ \\
\hline Hearings per Hour & $\begin{array}{l}1.229^{* * *} \\
(0.148)\end{array}$ & $\begin{array}{l}1.373^{* * *} \\
(0.194)\end{array}$ & $\begin{array}{l}1.748^{* * *} \\
(0.174)\end{array}$ & $\begin{array}{l}1.748^{* * *} \\
(0.174)\end{array}$ & $\begin{array}{l}1.786^{* * *} \\
(0.178)\end{array}$ \\
\hline Authorized Resolution & & $\begin{array}{c}18.719^{* * *} \\
(2.618)\end{array}$ & $\begin{array}{c}18.731^{* * *} \\
(2.616)\end{array}$ & $\begin{array}{l}18.731^{* * * *} \\
(2.616)\end{array}$ & $\begin{array}{l}18.717^{* * * *} \\
(2.620)\end{array}$ \\
\hline Warrant Resolution & & $\begin{array}{l}8.247^{*} \\
(3.226)\end{array}$ & $\begin{array}{l}8.134^{*} \\
(3.196)\end{array}$ & $\begin{array}{l}8.134^{*} \\
(3.196)\end{array}$ & $\begin{array}{l}8.116^{*} \\
(3.219)\end{array}$ \\
\hline Unattended Hearing & & $\begin{array}{c}-23.367^{* * *} \\
(2.231)\end{array}$ & $\begin{array}{l}-23.332^{* * *} \\
(2.227)\end{array}$ & $\begin{array}{c}-23.332^{* * *} \\
(2.227)\end{array}$ & $\begin{array}{l}-23.330^{* * *} \\
(2.235)\end{array}$ \\
\hline Life Crime & & $\begin{array}{c}8.801^{* * * *} \\
(2.651)\end{array}$ & $\begin{array}{c}8.899^{* * *} \\
(2.670)\end{array}$ & $\begin{array}{c}8.899^{* * *} \\
(2.670)\end{array}$ & $\begin{array}{c}8.909^{* * *} \\
(2.674)\end{array}$ \\
\hline Sexual Crime & & $\begin{array}{c}10.385^{* * *} \\
(2.003)\end{array}$ & $\begin{array}{c}10.429^{* * *} \\
(2.008)\end{array}$ & $\begin{array}{c}10.429^{* * *} \\
(2.008)\end{array}$ & $\begin{array}{c}10.462^{* * *} \\
(2.011)\end{array}$ \\
\hline Relative Humidity & & & $\begin{array}{l}0.204^{* *} \\
(0.073)\end{array}$ & $\begin{array}{l}0.204^{* *} \\
(0.073)\end{array}$ & $\begin{array}{l}0.225^{* *} \\
(0.086)\end{array}$ \\
\hline Temperature & & & $\begin{array}{l}0.506^{+} \\
(0.283)\end{array}$ & $\begin{array}{l}0.506^{+} \\
(0.283)\end{array}$ & $\begin{array}{c}0.150 \\
(0.384)\end{array}$ \\
\hline GDP & & & & $\begin{array}{l}-0.135^{* * *} \\
(0.027)\end{array}$ & $\begin{array}{l}-0.134^{* * *} \\
(0.031)\end{array}$ \\
\hline Particle Matter $\left(P M_{10}\right)$ & & & & & $\begin{array}{l}-0.013 \\
(0.061)\end{array}$ \\
\hline Sulfur Dioxide $\left(\mathrm{SO}_{2}\right)$ & & & & & $\begin{array}{l}0.008 \\
(0.801)\end{array}$ \\
\hline Carbon Monoxide $(\mathrm{CO})$ & & & & & $\begin{array}{l}0.996 \\
(7.191)\end{array}$ \\
\hline Ozone $\left(\mathrm{O}_{3}\right)$ & & & & & $\begin{array}{c}0.174 \\
(0.175)\end{array}$ \\
\hline R-squared & 0.109 & 0.280 & 0.281 & 0.281 & 0.281 \\
\hline No. Obs. & 9,328 & 9,328 & 9,328 & 9,328 & 9,328 \\
\hline
\end{tabular}

Table notes: ${ }^{* *} p<0.001,{ }^{* *} p<0.01,{ }^{*} p<0.05,{ }^{+} p<0.1$. IV regressions of the length of each judicial hearing on exposure to nitrogen oxides at the hour of the hearing. The instruments used for this specification are wind speed, wind direction, and atmospheric pressure. All regressions contain judge, courthouse, year, month, weekday, and hour fixed effects. Specification (1) contains nitrogen oxides and fixed effects. The other specifications add further controls while always keeping the covariates from the previous specification: (2) adds hearing specific covariates as the type of crime, the final resolution, and the hearing class; (3) adds weather covariates like temperature and relative humidity; (4) adds macroeconomic covariates at the city level; (5) adds additional measured pollutants. The reference crime is property crimes, reference hearing unattended hearing, and reference resolution Rescheduled cases — robust standard errors clustered at the judge in parentheses.

relationship between pollution and productivity by using hourly data, and the first to study in-work cognitive productivity for a task without breaks.

Given the importance of cognitive activities in modern societies, it seems crucial to account for the adverse effects of contaminants on the productivity of white-collar professions. The point estimates of this article are particular to one task and a specific type of mental process. However, even though point estimates may vary for other professions due to the use of different cognitive skills, isolation, or adaptation mechanisms, there is no reason why other individuals should not experience the negative shock to in-work productivity experienced by Mexican judicial workers when exposed to nitrogen oxides. Finally, because this is the first 


\begin{tabular}{lccccc}
\hline & \multicolumn{7}{c}{ Dependent variable: Hearings' length } \\
\cline { 2 - 6 } & $(1)$ & $(2)$ & $(3)$ & $(4)$ & $(5)$ \\
\hline Nitrogen Oxides $\left(N O_{x}\right)$ & 0.122 & $0.336^{* *}$ & $0.274^{* *}$ & $0.274^{* *}$ & $0.291^{*}$ \\
& $(0.151)$ & $(0.108)$ & $(0.105)$ & $(0.105)$ & $(0.116)$ \\
Nitrogen Oxide $(N O)$ & 0.184 & $0.391^{* * *}$ & $0.339^{* * *}$ & $0.339^{* * *}$ & $0.352^{* * *}$ \\
& $(0.133)$ & $(0.094)$ & $(0.085)$ & $(0.085)$ & $(0.090)$ \\
Nitrogen Dioxide $\left(N O_{2}\right)$ & 0.133 & $0.583^{+}$ & 0.323 & 0.323 & 0.263 \\
& $(0.403)$ & $(0.328)$ & $(0.275)$ & $(0.275)$ & $(0.327)$ \\
\hline No. Obs. & 9,328 & 9,328 & 9,328 & 9,328 & 9,328 \\
\hline
\end{tabular}

article showing a negative relationship between $N O_{x}$ and productivity, the results should be taken with a grain of salt in the sense that the study must be replicated for other professions and locations in order to provide scientific certainty on the findings.

\section{Robustness Tests}

I conduct several robustness exercises to support the causal inference of the econometric design. First, I analyze the effect of all other measured contaminants on the length of initial hearings. This exercise allows me to investigate if there is additional short term evidence on the relationship between pollution and cognitive productivity for other particles besides $N O_{x}$. Table 8 presents the results of changing the causal variable of all five specifications in the OLS regression design. In principle, no point estimate shows significance in the preferred single pollutant (4) and multipollutant specifications (5). The only contaminant close to significance is ozone. The results from these models do not carry any causal disassociation between these particles and productivity; they only show that for my specific sample and short time-window, I find no evidence of a connection between hearings' length and the other contaminants. The result also reduces worries concerning multicollinearity between $N O_{x}$ and the other pollutants. Additionally, I also run regression by aggregating the hourly data to daily values. Unfortunately, no pollutant seems significant at the daily level, perhaps because the aggregation takes away a large amount of the variation used for identification. 


\begin{tabular}{|c|c|c|c|c|c|}
\hline & \multicolumn{5}{|c|}{ Dependent variable: Hearings' length } \\
\hline & $(1)$ & $(2)$ & $(3)$ & (4) & $(5)$ \\
\hline Ozone $\left(O_{3}\right)$ & $\begin{array}{c}-0.077^{+} \\
(0.044)\end{array}$ & $\begin{array}{l}0.110^{+} \\
(0.058)\end{array}$ & $\begin{array}{c}0.110 \\
(0.088)\end{array}$ & $\begin{array}{c}0.110 \\
(0.088)\end{array}$ & $\begin{array}{c}0.196 \\
(0.162)\end{array}$ \\
\hline Coarse Particle Matter $\left(P M_{10}\right)$ & $\begin{array}{l}-0.029 \\
(0.025)\end{array}$ & $\begin{array}{c}0.031 \\
(0.031)\end{array}$ & $\begin{array}{c}0.026 \\
(0.032)\end{array}$ & $\begin{array}{c}0.026 \\
(0.032)\end{array}$ & $\begin{array}{l}-0.015 \\
(0.054)\end{array}$ \\
\hline Fine Particle Matter $\left(P M_{25}\right)$ & $\begin{array}{l}0.025 \\
(0.038)\end{array}$ & $\begin{array}{l}0.060^{+} \\
(0.036)\end{array}$ & $\begin{array}{c}0.027 \\
(0.037)\end{array}$ & $\begin{array}{c}0.027 \\
(0.037)\end{array}$ & $\begin{array}{l}0.013 \\
(0.039)\end{array}$ \\
\hline Carbon Monoxide $(\mathrm{CO})$ & $\begin{array}{l}-3.333 \\
(4526)\end{array}$ & $13.963^{*}$ & $\begin{array}{l}9.540 \\
(6122)\end{array}$ & 9.540 & 4.808 \\
\hline Sulfur Dioxide $\left(\mathrm{SO}_{2}\right)$ & $\begin{array}{c}(4.526) \\
-0.343^{* * *} \\
(0.099)\end{array}$ & $\begin{array}{c}(5.922) \\
0.006 \\
(0.118) \\
\end{array}$ & $\begin{array}{c}(6.122) \\
-0.081 \\
(0.083)\end{array}$ & $\begin{array}{c}(6.122) \\
-0.081 \\
(0.083)\end{array}$ & $\begin{array}{l}(6.861) \\
-0.013 \\
(0.500) \\
\end{array}$ \\
\hline No. Obs. & 11290 & 11290 & 11289 & 11289 & 10961 \\
\hline
\end{tabular}

Table notes: ${ }^{* * *} p<0.001,{ }^{* *} p<0.01,{ }^{*} p<0.05,{ }^{+} p<0.1$. OLS regressions of the length of each judicial hearing on exposure to ozone, coarse particle matter, fine particle matter, carbon monoxide, and sulfur dioxide at the hour of the hearing. All regressions contain courthouse, judge, year, month, weekday, and hour fixed effects. Specification (1) contains the contaminant, proxies for business at the courthouse, and the fixed effects. The other specifications add further controls while always keeping the covariates from the previous specification: (2) adds hearing specific covariates as the type of crime, the final resolution, and the type of hearing; (3) adds weather covariates like temperature and relative humidity; (4) adds macroeconomic covariates at the city level; Finally, (5) adds additional measured pollutants — robust standard errors clustered at the judge level in parentheses.

Next, I perform a robustness scenario where I separate crimes between violent and non-violent crimes. Violent crimes are sexual crimes, manslaughter, murder, assault, and kidnapping. Non-violent crimes are all others, including fraud, corruption, and family crimes. If pollution increases the probability of violent crimes as proposed by Bondy et al. (2018), and if violent crimes have longer hearing times, the regression results may be contaminated. Table 9 exhibits the coefficient of nitrogen oxides for each type of crime in the OLS design. Regression results show positive coefficients for both types of criminal activity, however, only non-violent crimes remain significant. I attribute the lack of significance of violent crimes to two reasons: first, the number of observations is smaller, and second, violent crimes are solved faster and likely require less negotiation inside the courtroom. Additionally, I analyze if the results are driven by one of the cities. The point estimate and significance of Monterrey remain quite similar to the base specification. For Mexico City, the coefficient grows in size but is statistically insignificant, mostly because of inferior data quality and a smaller sample. The table of coefficients is available upon request.

In a final exercise, I examine the relationship between hearings' length and $N O_{x}$ not only at the hour of the hearing but also between one and twelve hours before it. Figure 3 shows the results of this regression on the preferred single pollutant model. It is evident from the image that significance only concentrates on the level of exposure at the time of the hearing. The reason for the lack of significance may be biological or driven by the significant inter-hour 


\begin{tabular}{|c|c|c|c|c|c|c|}
\hline & \multicolumn{6}{|c|}{ Dependent variable: Hearings' length } \\
\hline & Crime & (1) & (2) & (3) & (4) & $(5)$ \\
\hline Nitrogen Oxides $\left(N O_{x}\right)$ & Non Violent & $0.249^{* *}$ & $\begin{array}{c}0.346^{* * *} \\
(0.088)\end{array}$ & $\begin{array}{c}0.316^{* * *} \\
(0.091)\end{array}$ & $0.316^{* * *}$ & $\begin{array}{r}0.300^{* *} \\
(0.096)\end{array}$ \\
\hline Nitrogen Oxides $\left(N O_{x}\right)$ & Violent & $\begin{array}{c}0.218 \\
(0.157)\end{array}$ & $\begin{array}{c}0.165 \\
(0.179)\end{array}$ & $\begin{array}{c}0.079 \\
(0.183)\end{array}$ & $\begin{array}{c}0.079 \\
(0.183)\end{array}$ & $\begin{array}{c}0.162 \\
(0.201)\end{array}$ \\
\hline \multicolumn{7}{|l|}{ Violent crime: } \\
\hline No. Obs. & - & 2841 & 2841 & 2841 & 2841 & 2841 \\
\hline \multicolumn{7}{|l|}{ Non Violent crime: } \\
\hline No. Obs. & - & 7670 & 7670 & 7670 & 7670 & 7670 \\
\hline
\end{tabular}

Table notes: ${ }^{* * *} p<0.001,{ }^{* *} p<0.01,{ }^{*} p<0.05,{ }^{+} p<0.1$. OLS regressions of the length of each judicial hearing on exposure to nitrogen oxides at the hour of the hearing.All regressions contain courthouse, judge, year, month, weekday, and hour fixed effects. Specification (1) contains the contaminant, proxies for business at the courthouse, and the fixed effects. The other specifications add further controls while always keeping the covariates from the previous specification: (2) adds hearing specific covariates as the type of crime, the final resolution, and the type of hearing; (3) adds weather covariates like temperature and relative humidity; (4) adds macroeconomic covariates at the city level; Finally, (5) adds additional measured pollutants — robust standard errors clustered at the judge level in parentheses.

variation in the causal variable.

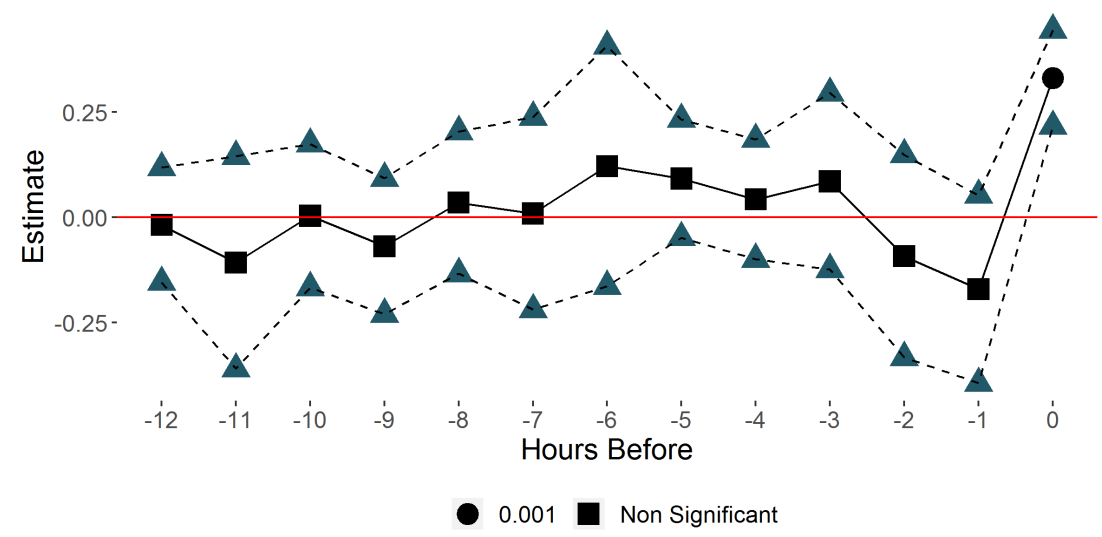

Figure 3: Point estimates for different lag values

Notes: This figure shows the point estimates of the prefered single pollutant regression on $N O_{x}$ at the time of the hearing and twelve lag hours before the hearing. Standard errors $\times 2$ in dotted lines.

\subsection{Placebos}

I present three different placebo tests to test if my results come from a deficiency in the empirical methodology. First, I perform temporal randomizations of the causal variable for four different time-windows: yearly, monthly, weekly, and for the whole study period. Specifically, I randomize the values of exposure to all contaminants across each time window, i.e., in the weekly time window, I interchange the value of exposure between hearings happening in the same week and at the same courthouse. Table 11 present the results of this exercise for the five 
specifications and $N O_{x}$. Except for some significance in the first specification for the monthly time-window, all coefficients appear insignificant and with mixed signs in the preferred multipollutant (5) and single pollutant (4) models.

Table 10: OLS results for temporal randomizations

\begin{tabular}{|c|c|c|c|c|c|c|}
\hline & \multicolumn{6}{|c|}{ Dependent variable: Hearings' length } \\
\hline & $\begin{array}{c}\text { Time } \\
\text { Window }\end{array}$ & (1) & (2) & (3) & (4) & $(5)$ \\
\hline Nitrogen Oxides & Study & $\begin{array}{l}-0.033 \\
(0.052)\end{array}$ & $\begin{array}{l}0.103^{+} \\
(0.059)\end{array}$ & $\begin{array}{l}0.100^{+} \\
(0.060)\end{array}$ & $\begin{array}{l}0.100^{+} \\
(0.060)\end{array}$ & $\begin{array}{c}0.113 \\
(0.071)\end{array}$ \\
\hline Nitrogen Oxides & Yearly & $\begin{array}{l}-0.060 \\
(0.052)\end{array}$ & $\begin{array}{c}0.069 \\
(0.060)\end{array}$ & $\begin{array}{c}0.071 \\
(0.060)\end{array}$ & $\begin{array}{c}0.071 \\
(0.060)\end{array}$ & $\begin{array}{c}0.026 \\
(0.071)\end{array}$ \\
\hline Nitrogen Oxides & Monthly & $\begin{array}{c}-0.161^{* *} \\
(0.053)\end{array}$ & $\begin{array}{l}-0.077 \\
(0.061)\end{array}$ & $\begin{array}{l}-0.079 \\
(0.061)\end{array}$ & $\begin{array}{l}-0.079 \\
(0.061)\end{array}$ & $\begin{array}{l}-0.041 \\
(0.072)\end{array}$ \\
\hline Nitrogen Oxides & Weekly & $\begin{array}{l}-0.085 \\
(0.053)\end{array}$ & $\begin{array}{c}0.039 \\
(0.061) \\
\end{array}$ & $\begin{array}{c}0.040 \\
(0.061) \\
\end{array}$ & $\begin{array}{c}0.040 \\
(0.061) \\
\end{array}$ & $\begin{array}{c}0.076 \\
(0.073) \\
\end{array}$ \\
\hline
\end{tabular}

Table notes: ${ }^{* * *} p<0.001,{ }^{* *} p<0.01,{ }^{*} p<0.05,{ }^{+} p<0.1$. OLS regressions of the length of each judicial hearing on exposure to nitrogen oxides dioxide at the hour of the hearing. All regressions contain judge, courthouse, year, month, weekday, and hour fixed effects. Specification (1) contains nitrogen oxides and fixed effects. The other specifications add further controls while always keeping the covariates from the previous specification: (2) adds hearing specific covariates as the type of crime, the final resolution, and the type of hearing; (3) adds weather covariates like temperature and relative humidity; (4) adds macroeconomic covariates at the city level; (5) adds additional measured pollutants. Robust standard errors clustered at the judge in parentheses.

Next, I analyze the effect of lags at three different time-windows: Twelve hours, one day, and one week before the hearing. In principle, the variation of pollution twelve hours, one day, and one week before the hearing should not affect its length. Table 10 exhibits the outcomes of this exercise. There is no significance for the twelve hours and weekly time windows. However, for the daily measure, there is borderline significance because of the strong intraday seasonality of $N O_{x}$.

Table 11: OLS results for lags

\begin{tabular}{|c|c|c|c|c|c|c|}
\hline & \multicolumn{6}{|c|}{ Dependent variable: Hearings' length } \\
\hline & $\begin{array}{c}\text { Lag } \\
\text { Window }\end{array}$ & (1) & (2) & (3) & (4) & (5) \\
\hline Nitrogen Oxides & Twelve Hours & $\begin{array}{l}-0.068 \\
(0.063)\end{array}$ & $\begin{array}{c}0.073 \\
(0.048)\end{array}$ & $\begin{array}{c}0.067 \\
(0.046)\end{array}$ & $\begin{array}{c}0.067 \\
(0.046)\end{array}$ & $\begin{array}{c}0.085 \\
(0.139)\end{array}$ \\
\hline Nitrogen Oxides & Daily & $\begin{array}{r}-0.038 \\
(0.058)\end{array}$ & $\begin{array}{l}0.100^{*} \\
(0.050)\end{array}$ & $\begin{array}{l}0.078^{+} \\
(0.044)\end{array}$ & $\begin{array}{l}0.078^{+} \\
(0.044)\end{array}$ & $\begin{array}{l}0.116^{+} \\
(0.071)\end{array}$ \\
\hline Nitrogen Oxides & Weekly & $\begin{array}{l}-0.047 \\
(0.064)\end{array}$ & $\begin{array}{c}0.093^{*} \\
(0.045)\end{array}$ & $\begin{array}{c}0.064 \\
(0.041)\end{array}$ & $\begin{array}{c}0.064 \\
(0.041)\end{array}$ & $\begin{array}{l}-0.025 \\
(0.069)\end{array}$ \\
\hline
\end{tabular}

Table notes: ${ }^{* * *} p<0.001,{ }^{* *} p<0.01,{ }^{*} p<0.05,{ }^{+} p<0.1$. OLS regressions of the length of each judicial hearing on exposure to nitrogen oxides at the hour of the hearing. All regressions contain individual, year, month, weekday, and hour fixed effects. Specification (1) contains nitrogen oxides and fixed effects. The other specifications add further controls while always keeping the covariates from the previous specification: (2) adds hearing specific covariates as the type of crime, the final resolution, and the type of hearing; (3) adds weather covariates like temperature and relative humidity; (4) adds macroeconomic covariates at the city level; (5) adds additional measured pollutants. Robust standard errors clustered at the judge in parentheses.

Finally, I do spatial randomizations by exchanging the pollution values of the stations 
located in the city of Monterrey with the pollution measures of stations in Mexico City. Productivity in Monterrey should not be affected by hourly variations in Mexico City. table 12 shows the results from this exercise. The placebo test shows insignificance for all specifications.

\begin{tabular}{lccccc}
\hline & \multicolumn{5}{c}{ Dependent variable: Hearings, length } \\
\cline { 2 - 6 } & $(1)$ & $(2)$ & $(3)$ & $(4)$ & $(5)$ \\
\hline Nitrogen Oxides & -0.032 & -0.004 & -0.014 & -0.014 & 0.003 \\
& $(0.029)$ & $(0.033)$ & $(0.053)$ & $(0.053)$ & $(0.098)$ \\
\hline No. Obs. & 11290 & 11290 & 11289 & 11289 & 10961 \\
\hline
\end{tabular}

Table notes: ${ }^{* * *} p<0.001,{ }^{* *} p<0.01,{ }^{*} p<0.05,{ }^{+} p<0.1$. OLS regressions of the length of each judicial hearing on exposure to nitrogen oxides. All regressions contain individual, year, month, weekday, and hour fixed effects. Specification (1) contains nitrogen oxides and fixed effects. The other specifications add further controls while always keeping the covariates from the previous specification: (2) adds hearing specific covariates as the type of crime, the final resolution, and the type of hearing; (3) adds weather covariates like temperature and relative humidity; (4) adds macroeconomic covariates at the city level; Finally, (5) adds additional measured pollutants. Robust standard errors clustered at the judge in parentheses.

\section{Conclusion}

I propose that nitrogen oxides affect the productivity of lawyers, judges, and prosecutors participating in Mexican court hearings and approximate the productivity value with the time it takes participating workers to resolve each trial. The empirical methodology uses pollution and weather data from city-wide monitoring stations alongside court data on the specific characteristics of each hearing to infer causality. I propose that exposure to $N O_{x}$ increases the length of judicial hearings through its effect on the cognitive productivity of hearing participants.

Existing research on the relationship between pollution and productivity concentrates on labor absences, or when focusing on productivity at work, it concentrates on physical labor, job quality, or fails to account for breaks. This article differentiates from previous literature in several respects. First, it analyzes the relationship between productivity and a previously disregarded pollutant: nitrogen oxides. Second, it is the first study explaining the causal link between pollution and productivity by using hourly variations to identify the short term effect of exposure, and third, it measures the impact of exposure on an activity that is free from discretionary breaks.

I infer causality by using panel techniques that exploit the high temporal granularity of the data and the widespread spatial distribution of courthouses across both cities. Time and individual fixed effects allow me to control for time consistent unobservables that could con- 
taminate the results of the regression design. Additionally, the empirical methodology control for a broad set of relevant covariates, including weather, trial characteristics, macroeconomic variables, and workloads. I address the issue of spurious correlation between $N O_{x}$ and other particles by specifying multipollutant models that control for all other measured criteria pollutants $\left(\mathrm{PM}_{10}, \mathrm{SO}_{2}, \mathrm{CO}\right.$, and $\left.\mathrm{O}_{3}\right)$. Additionally, I run an instrumental variable design to reduce the probability of time-varying unobservables tainting the point estimates of the ordinary least squares regressions.

The main results from the study point to an increase in the mean length of judicial hearings of $3.68 \%$ after one standard deviation jump in the concentration of $N O_{x}$. Point estimates increase in size in the multipollutant and instrumental variable specifications. These results are equivalent to an increase of 1.55 minutes from the average length (40 minutes), and although in principle 1.55 minutes don't seem like much, aggregating them across trials can show very significant shocks to labor productivity. For example, if we compare the levels of pollution between all hearings happening at ten versus six am. We will see that during my study period (2015-2017) 1781 cases occurred at $10 \mathrm{am}$, considering that the level of $N O_{x}$ at 10 am is two standard deviations larger than at 6 am, this will imply a total lost 3.8 working days because of the effect of exposure on hearing participants at ten in the morning. Furthermore, it is also likely that this effect will affect other white-collar professions across different urban centers and thus impose a significant economic burden across the society.

Robustness checks show that results appear to be driven by non-violent offenses and the city of Monterrey. Moreover, the results are consistent with three different placebo tests, one randomizing exposure across time, another interchanging the pollution values of Mexico City and Monterrey, and a final one analyzing the effect of lagged exposure values on current hearing times.

The hypothesis that nitrogen oxides affect the in-work productivity of judicial workers is of high policy relevance for two main reasons. First, the upcoming revolution on labor automation should increase the labor share of cognitive activities, making the impact of external shocks on the productivity of white-collar professions more relevant. Second, policies designed to reduce the air concentration of nitrogen oxides are not as widespread or continuously updated as those for other pollutants, for example, Mexico City has not updated the pollution limit for $\mathrm{NO}_{2}$ since 1993, probably because of the lack of epidemiological certainty on its health effects or because surrogate contaminants shadow its impact on human activities. 
From a policy and economic perspective, it is advisable to analyze exposure consequences of $N O_{x}$ on cognitive productivity to incorporate them in the design and implementation of pollution standards and environmental policies. One caveat of the study is that without in-lab controlled experiments, it is not possible to claim that the effect does not come from unobservable particles emitted alongside nitrogen oxides nor to pinpoint the exact medical reason behind the results. As this is the first paper showing an empirical relationship between nitrogen oxides and cognitive productivity, it should be taken with a grain of salt; future work calls for the analysis of exposure on other professions and different locations alongside a better understanding of the physiological reasons behind this connection.

\section{References}

Aragon F. M., Miranda J. J., and Oliva P. (2016) Particulate matter and labor supply: the role of caregiving and non-linearities: The World Bank.

Archsmith J., Heyes A., and Saberian S. (2018) Air quality and error quantity: Pollution and performance in a high-skilled, quality-focused occupation. Journal of the Association of Environmental and Resource Economists, 5(4): 827-863.

Bharadwaj P., Gibson M., Zivin J. G., and Neilson C. (2017) Gray matters: Fetal pollution exposure and human capital formation. Journal of the Association of Environmental and Resource Economists, 4(2): 505-542.

Bondy M., Roth S., and Sager L. (2018) Crime is in the Air: The Contemporaneous Relationship between Air Pollution and Crime. IZA Discussion Paper No. 11492.

Brand P., Bertram J., Chaker A., Jörres R., Kronseder A., Kraus T., and Gube M. (2016) Biological effects of inhaled nitrogen dioxide in healthy human subjects. International archives of occupational and environmental health, 89(6): 1017-1024.

Chang T., Graff Zivin J., Gross T., and Neidell M. (2016) Particulate pollution and the productivity of pear packers. American Economic Journal: Economic Policy, 8(3): 141-69.

Chang T. Y., Graff Zivin J., Gross T., and Neidell M. (2019) The effect of pollution on worker productivity: evidence from call center workers in China. American Economic Journal: Applied Economics, 11(1): 151-72. 
David H. (2015) Why are there still so many jobs? The history and future of workplace automation. Journal of economic perspectives, 29(3): 3-30.

De Mesnard L. (2013) Pollution models and inverse distance weighting: Some critical remarks. Computers \& Geosciences, 52: 459-469.

DOF (2014) Codigo Nacional de Procedimientos Penales. Access at: http://www. diputados.gob.mx/LeyesBiblio/ref/cnpp/CNPP_orig_05mar14.pdf

(2017) Ley Federal de Transparencia y Acceso a la Informacion Publica. Access at: http://www .diputados.gob.mx/LeyesBiblio/ref/cnpp/CNPP_orig_05mar14.pdf.

Graff Zivin J. and Neidell M. (2012) The impact of pollution on worker productivity. American Economic Review, 102(7): 3652-73.

Halliday T. J., Lynham J., and de Paula Á. (2018) Vog: using volcanic eruptions to estimate the health costs of particulates. The Economic Journal, 129(620): 1782-1816.

Hanna R. and Oliva P. (2015) The effect of pollution on labor supply: Evidence from a natural experiment in Mexico City. Journal of Public Economics, 122: 68-79.

Hasselblad V., Eddy D. M., and Kotchmar D. J. (1992) Synthesis of environmental evidence: nitrogen dioxide epidemiology studies. Journal of the Air \& Waste Management Association, 42(5): 662-671.

Hesterberg T. W., Bunn W. B., McClellan R. O., Hamade A. K., Long C. M., and Valberg P. A. (2009) Critical review of the human data on short-term nitrogen dioxide (NO2) exposures: evidence for NO2 no-effect levels. Critical reviews in toxicology, 39(9): 743-781.

Heyes A., Neidell M., and Saberian S. (2016) The effect of air pollution on investor behavior: Evidence from the S\&P 500.Technical report, National Bureau of Economic Research.

Howden-Chapman P., Pierse N., Nicholls S., Gillespie-Bennett J., Viggers H., Cunningham M., Phipps R., Boulic M., Fjällström P., Free S. et al. (2008) Effects of improved home heating on asthma in community dwelling children: randomised controlled trial. Bmj, 337: a1411.

INEGI (2014) Clasificacion Mexicana de Delitos. Access at: http://www.diputados.gob. $\mathrm{mx} /$ documentos/Congreso_Nacional_Legislativo/Doc/CMD_Integrado.pdf. 
Iskandar A., Andersen Z. J., Bønnelykke K., Ellermann T., Andersen K. K., and Bisgaard H. (2012) Coarse and fine particles but not ultrafine particles in urban air trigger hospital admission for asthma in children. Thorax, 67(3): 252-257.

Jayachandran S. (2009) Air quality and early-life mortality evidence from Indonesiaâs wildfires. Journal of Human resources, 44(4): 916-954.

Kaplan M. S. (2004) Personal exposure to nitrogen dioxide and the severity of virus-induced asthma in children. Pediatrics, 114(Supplement 1): 537-538.

Kim Y., Manley J., and Radoias V. (2017) Medium-and long-term consequences of pollution on labor supply: evidence from Indonesia. IZA Journal of Labor Economics, 6(1): 5.

Knittel C. R., Miller D. L., and Sanders N. J. (2016) Caution, Drivers! Children Present: Traffic, Pollution, and Infant Health. Review of Economics and Statistics, 98(2): 350-366.

Lavy V., Ebenstein A., and Roth S. (2014) The impact of short term exposure to ambient air pollution on cognitive performance and human capital formation.Technical report, National Bureau of Economic Research.

Lovbland G., F. P., van Aalast R., Allegrini I B. R., A. D., L. E., I. F., A. H., M. H., T. L., van Leeuwen R., Nilson M. P. V., E. D. S., and de Santis F (1997) Position paper on Air Quality: nitrogen dioxide. Directorate-General, XI, EU.

Meyer S. and Pagel M. (2017) Fresh Air Eases Work-The Effect of Air Quality on Individual Investor Activity.Technical report, National Bureau of Economic Research.

Moretti E. and Neidell M. (2011) Pollution, health, and avoidance behavior evidence from the ports of Los Angeles. Journal of human Resources, 46(1): 154-175.

Oberdörster G., Sharp Z., Atudorei V., Elder A., Gelein R., Kreyling W., and Cox C. (2004) Translocation of inhaled ultrafine particles to the brain. Inhalation toxicology, 16(6-7): 437445.

Oikonen M., Laaksonen M., Laippala P., Oksaranta O., Lilius E.-M., Lindgren S., RantioLehtimäki A., Anttinen A., Koski K., and Erälinna J.-P. (2003) Ambient air quality and occurrence of multiple sclerosis relapse. Neuroepidemiology, 22(1): 95-99. 
Ostro B., Lipsett M., Mann J., Braxton-Owens H., and White M. (2001) Air pollution and exacerbation of asthma in African-American children in Los Angeles. Epidemiology: 200208.

Pitocco D., Zaccardi F., Di Stasio E., Romitelli F., Santini S. A., Zuppi C., and Ghirlanda G. (2010) Oxidative stress, nitric oxide, and diabetes. The review of diabetic studies: RDS, $7(1): 15$.

Ranft U., Schikowski T., Sugiri D., Krutmann J., and Krämer U. (2009) Long-term exposure to traffic-related particulate matter impairs cognitive function in the elderly. Environmental research, 109(8): 1004-1011.

Rosales-Rueda M. and Triyana M. (2018) The persistent effects of early-life exposure to air pollution: Evidence from the Indonesian forest fires. Journal of Human Resources: 01178497R1.

Schikowski T., Vossoughi M., Vierkötter A., Schulte T., Teichert T., Sugiri D., Fehsel K., Tzivian L., Bae I.-s., Ranft U. et al. (2015) Association of air pollution with cognitive functions and its modification by APOE gene variants in elderly women. Environmental research, 142: $10-16$.

Shepard D. (1968) A two-dimensional interpolation function for irregularly-spaced data. in Proceedings of the 1968 23rd ACM national conference: 517-524, ACM.

Sunyer J., Puig C., Torrent M., Garcia-Algar O., Calicó I., Muñoz-Ortiz L., Barnes M., and Cullinan P. (2004) Nitrogen dioxide is not associated with respiratory infection during the first year of life. International journal of epidemiology, 33(1): 116-120.

Tunnicliffe W., Burge P., and Ayres J. (1994) Effect of domestic concentrations of nitrogen dioxide on airway responses to inhaled allergen in asthmatic patients. The Lancet, 344(89398940): 1733-1736.

Wei T., Chen C., Hou J., Xin W., and Mori A. (2000) Nitric oxide induces oxidative stress and apoptosis in neuronal cells. Biochimica et Biophysica Acta (BBA)-Molecular Cell Research, 1498(1): 72-79. 